\title{
Prensa y divulgación de la historia patria en Colombia: la obra de Pedro María Ibáñez en publicaciones literarias e ilustradas, 1882-1919*
}

Recibido: 04/02/2019 | Revisado: 01/04/2019 | Aceptado: 08/05/2019 DOI: $10.17230 /$ co-herencia.16.31.10

Gabriel Samacá**

gsamaca@colmex.mx

\begin{abstract}
Resumen En la Bogotá de mediados del siglo XIX e inicios del xx, la prensa literaria e ilustrada fue una condición de posibilidad para el surgimiento y posicionamiento de la historia patria como saber legítimo. Gracias a estos impresos, los hombres de letras contaron con un espacio para difundir trabajos que, por su extensión y naturaleza, se diferenciaron de las noticias de actualidad de la naciente prensa política e informativa. A través del análisis de la obra histórica que el médico e historiador Pedro María Ibáñez publicó en prensa, en el presente artículo se sostiene que las élites letradas intentaron dar forma a una parte de la opinión pública, para que trascendiera las disputas partidistas producto de una fuerte pugnacidad política que devino en guerras civiles. El artículo se basa en la revisión sistemática de periódicos ilustrados, revistas literarias y culturales de la época, y una amplia bibliografía de contexto que permite abordar una faceta desconocida en el proceso de constitución y divulgación del saber histórico en Colombia.
\end{abstract}

\section{Palabras clave:}

Prensa ilustrada, revistas literarias, Pedro María Ibáñez, historia patria, historiografía.

\section{Press and dissemination of historia patria in Colombia: the work of Pedro María lbáñez in literary and illustrated publications, 1882-1919}

\footnotetext{
Abstract In the Bogota of the mid-nineteenth and early twentieth centuries, the literary and illustrated press was a condition of possibility of the emergence and positioning of the so-called historia patria as legitimate knowledge. Thanks to these printed materials, men of letters had a space
}

* Este artículo hace parte de la tesis doctoral titulada: "Ibáñez, un historiador a la moderna: escritura, circulación y lecturas de la historia patria desde Bogotá, 18781923", que se encuentra en proceso de elaboración en el Centro de Estudios Históricos de El Colegio de México, bajo la dirección del doctor Marco Palacios Rozo. Agradezco a los evaluadores las correcciones sugeridas y a Natalia Gutiérrez Urquijo por su cuidadosa lectura.

** Historiador de la Universidad Industrial de Santander, maestro en Historia de la Universidad Industrial de Santander, y maestro y doctorando en Historia por El Colegio de México, México. ORCID: 0000-0002$8319-2073$ 
to disseminate works that, given their length and nature, differed from the latest news found in the nascent political and informative press. Through the analysis of the historical work published by physician and historian Pedro María Ibáñez in the press, this paper argues that literate elites tried to shape a part of the public opinion, so that it transcended the partisan disputes resulting from a strong political pugnacity that turned into civil wars. The paper is the result of a systematic review of illustrated newspapers, literary and cultural journals of the time, as well as of an extensive contextual bibliography which allows addressing an unknown face of the process of creation and dissemination of historical knowledge in Colombia.

\section{Keywords:}

Illustrated press, literary magazines, Pedro María Ibáñez, historia patria, historiography.

A lo largo y ancho del mundo, la segunda mitad del siglo XIX fue el momento del periodismo, la historia y la invención de las naciones (Hill, 2008). ${ }^{1}$ Durante este lapso, la prensa llegó a ser un instrumento de autoobservación de la sociedad, en un contexto de ampliación radical de las comunicaciones (Osterhammel, 2015, pp. 58-71). Pese a la existencia de la censura política y de mercado, los periódicos trascendieron los sectores cultos y letrados para crear un espacio público más amplio que incorporó nuevos lectores y contenidos (Lyons, 2004, pp. 539-589). Igualmente, se presenció un cambio crucial en las formas de concebir el pasado, a partir de un modelo liberal eurocéntrico que buscó legitimar la nación como nueva entidad política y cultural dominante (Conrad, 2017, pp. 27-32). La definición de nuevas comunidades imaginadas corrió de forma paralela con la estandarización progresiva de la escritura de la historia, en la que diferentes soportes impresos jugaron un papel central junto a la lengua, los museos, la literatura, los censos y la cartografía, entre otros dispositivos (Anderson, 1993).

A partir de este marco, en este artículo, la atención se centra en un tipo de prensa que intentó dar forma a una parte de la opinión pública colombiana, a finales del siglo XIX, con el fin de trascender las

1 Koselleck (2004) situó, para Europa, la aparición del singular colectivo "historia" entre 1750 y 1850 , período que remite a una lenta transición de la historia como maestra de vida a la ciencia histórica. A partir de 1850, dicho proceso experimentó una fase de estabilización y extensión a lo largo de un mundo cada vez más conectado. 
disputas partidistas que derivaron en una fuerte pugnacidad política y guerras civiles (Posada, 2008, pp. 469-487). La prensa literaria, en general, y la ilustrada como una de sus principales variantes, surgieron bajo el principio de ser "apolíticas" y "patrióticas", para ofrecer al público un alimento espiritual que permitiera conseguir el anhelado progreso material y moral (Villamizar, 2014, pp. 185-199). ${ }^{2}$ Sin importar el medio, liberales y conservadores practicaron esta forma de periodismo, con el fin de desplegar un ideario civilizatorio que mantuviera un orden social y geográfico jerarquizado, con epicentro en la capital del país. ${ }^{3}$ En este contexto, surge la pregunta sobre cuál fue la relación entre la historia, como saber en formación, y su divulgación a través de la prensa literaria e ilustrada.

Para intentar dar una respuesta, se abordará la actividad periodística del médico e historiador bogotano Pedro María Ibáñez (18541919), en este tipo de prensa, entre 1882 y $1919 .{ }^{4}$ Letrado de figuración secundaria, respecto al predominio de los gramáticos, en la república letrada de la "Atenas suramericana", Ibáñez transitó por los proyectos periodísticos más importantes de aquellos años aportando desde su pluma un componente histórico a la constitución de una opinión pública de élite. ${ }^{5}$ De lo que se trata es de apreciar cómo el conocimiento histórico en la prensa hizo parte de las ideas que circularon entre determinados sectores letrados bogotanos, acompañando y complementando otros mecanismos de configuración de

2 Al respecto, en un periódico literario dirigido por el médico e historiador bogotano José María Quijano Otero, se puede leer: "En medio de ese entusiasmo [el de la llegada de los impresos a los poblados], no falta también quien pida el periódico literario. Este tal no busca ajos ni mostaza; quiere un alimento sano y ligero; algo que distraiga las horas largas de las poblaciones pequeñas; algo que deleite é instruya sin fatigar el espíritu, á su esposa y sus hijas" (El Eco Literario, 1873). Sobre la importancia de la prensa literaria, ver Vasco (2016, pp. 87-89).

3 Sobre el concepto de civilización en la época, ver Zermeño (2017, pp. 193-211).

4 Ibáñez se destacó como secretario de la Sociedad de Medicina y Ciencias Naturales, y de la Academia Nacional de Historia, además, como director del Boletín de Historia y Antigüedades. Autor de diversas obras de historia, es reconocido por elaborar la primera historia de la medicina en el país (1882) y uno de los trabajos más importantes sobre la historia capitalina, titulado Crónicas de Bogotá y sus inmediaciones (1891). Ver Laverde (1895, pp. 204-206.)

5 El debate sobre el modelo habermasiano de surgimiento y desarrollo de la opinión pública es muy amplio. Algunas de las referencias imprescindibles son: Habermas (1997, pp. 41-123), Van Horn Melton (2009, pp. 26-32), Guerra y Lempériére (1998, pp. 5-21), Zermeño (2017, pp. 45-65), Piccato (2005, pp. 9-39), y Palti (2007, pp. 161-202). 
una memoria nacional, como los museos, las conmemoraciones, la poesía, el drama patriótico y las obritas de uso escolar (Cardona, 2016; Pérez, 2010, pp. 75-103; Pérez, 2015, pp. 101-184; Rincón, 2014, pp. 63-96).

El texto se estructura en cuatro apartados. En el primero, se describirá, brevemente, qué se entendía por prensa literaria e ilustrada en los años de estudio, a partir de las imágenes que ofrecieron los redactores de algunos de los principales medios de este tipo. En segunda instancia, se aludirá a la participación de Ibáñez en el primer periódico ilustrado que tuvo Colombia, el Papel Periódico Ilustrado (1881-1888), así como en algunos medios que se asumieron como sus herederos. En tercer lugar, se abordarán las relaciones que mantuvo Ibáñez con algunas publicaciones literarias, especialmente revistas culturales, las cuales sirvieron de vehículo para posicionar la historia patria. Por último, y en contravía de lo planteado por sus gestores, se estudiarán algunos suplementos literarios que hicieron parte de periódicos abiertamente vinculados al liberalismo moderado, poniendo el conocimiento histórico al servicio de la política partidista.

\section{Una prensa para aplacar los conflictos políticos y construir patria}

Los estudios sobre la prensa literaria en Colombia se han concentrado en su papel de medio configurador de la literatura, lo que ha limitado la labor de desentrañar toda su complejidad y riqueza (Bedoya, 2011, p. 92). La mayoría de trabajos se enfocan en la "función visibilizadora" de autores, temas, obras, corrientes, estilos y actitudes literarias que regularon un campo en formación y dieron origen a ciertos cánones en el ejercicio de la actividad literaria (Castaño, 2002, p. 271). Una de las principales falencias de este abordaje reside en desconocer los diferentes soportes materiales de lo literario, entre los que se destacaron los semanarios ilustrados, los quincenarios o las revistas culturales. ${ }^{6}$ En contraste con la historiografía mexicana,

6 Las más recientes investigaciones lideradas por el grupo de investigación "Colombia: tradiciones de la palabra" de la Universidad de Antioquia procuran estudiar los diferentes formatos, corrientes literarias y géneros. Al respecto, se pueden ver los números monográficos 43 y 47 de los Anales de Literatura Hispanoamericana, de 2014 y 2018, respectivamente. 
española o argentina, la colombiana ha descuidado el estudio de la prensa de la segunda mitad del siglo XIX, predominando la transición del Antiguo Régimen a la República (Ortega y Chaparro, 2012).

En Bogotá, a partir de los años cuarenta del siglo XIX, algunos jóvenes de familias acomodadas y amantes de las letras crearon espacios para conversar sobre el papel de la literatura en un país que se debatía en agudas y "estériles" confrontaciones políticas. Desde aquel entonces, los diferentes periódicos literarios dieron cabida a la poesía romántica, los cuadros de costumbres y, en general, todos aquellos escritos que buscaban la moralización de los lectores, especialmente de las mujeres y los jóvenes (Otero, 1998, pp. 109-140). Para José María Vergara y Vergara (1831-1872), director de la tertulia y el periódico El Mosaico, este tipo de prensa estaba llamada a mantenerse alejada de las pasiones políticas, aplacar los ánimos pendencieros, resaltar la riqueza natural que la "Providencia" había puesto en el suelo patrio y enaltecer los valores trascendentales, más allá del afán de lucro que caracterizaba la emergente sociedad capitalista?

Este llamado a dejar de lado la inquina e intriga partidista no puede ser entendido como expresión de un desinterés político por parte de los promotores de la prensa literaria. A su manera, y desde posiciones conservadoras, tradicionalistas y católicas, sentarían las bases culturales de lo que sería la Regeneración (1878-1900), a partir de la definición de la literatura nacional. En 1889, José Tomás Gaibrois (1889a), director de la revista Colombia Ilustrada, reiteró cómo la literatura, en un sentido amplio, solo había podido desarrollarse en el país durante los períodos de paz y tranquilidad social. Para este letrado, amigo personal de Ibáñez, la prensa ilustrada representaba un paso adelante respecto al periodismo político, informativo e incluso literario, al incorporar los avances técnicos del grabado como elemento central de los medios de comunicación de fin de siglo (Gaibrois, 1889b).

Si bien la prensa literaria inició en Bogotá a mediados del siglo XIX, el desarrollo de las publicaciones ilustradas fue posible en el último cuarto de la centuria, gracias a la introducción que realizó

7 "Las cuestiones políticas i los odios personales las dejamos para mejor ocasión; por ahora publicaremos únicamente lo que se nos envíe, relacionado con la[s] ciencias i las glorias del país donde nacimos" (El Mosaico, 1858). 
el artista y político conservador Alberto Urdaneta (1845-1887) tras una estancia en París (Moreno, 1972). La preocupación por difundir los logros científicos, artísticos, culturales y económicos del país hizo del uso de las imágenes en la prensa una novedad. La xilografía también fue utilizada para difundir retratos de las glorias nacionales, "vistas exteriores" de lugares emblemáticos y tipos sociales regionales (Fajardo, 1998, pp. 110-131). Además, sirvió para promover imágenes positivas de la nación hacia el exterior y generar orgullo entre las élites, con base en las opiniones de una capa de conocedores que se erigieron como críticos de arte (Yujnovsky, 2011). De esta manera, las publicaciones ilustradas y literarias cumplieron la función social de servir de intermediarias y creadoras de los agentes que conformaron los ámbitos de la creación intelectual en el país (Martínez, 2012, pp. 77-96).

Una de las formas que tomó el periodismo literario e ilustrado fue la revista cultural. Este tipo de impreso se enfocó en la publicación de escritos sobre ciencia, política, curiosidades, historias moralizantes y temas de actualidad (Pita, 2003, p. 5; Illades, 2004, pp. 51-64). Este medio proponía visiones particulares de la realidad, de acuerdo a los arreglos que alcanzaban los redactores y colaboradores en momentos específicos. A la par, sirvió de vitrina para nuevos escritores, facilitando la comunicación al interior de la república de las letras a nivel nacional e internacional. Las revistas culturales fueron el resultado de sacrificios y ambiciones personales de individuos que pretendieron ir más allá de las disputas partidistas enarbolando la bandera del progreso moral (Melo, 2005, pp. 1-22).

En 1881, el político liberal-conservador y hombre de letras José María Samper (1828-1888) refirió las principales características de estas revistas que se encontraban a medio camino entre el libro y la hoja periódica. De acuerdo con este personaje, tales impresos exigían una lectura más atenta a la reflexión como parte de su apuesta por articular el cosmopolitismo, los temas nacionales y la armonía social. En sus propias palabras:

La revista es, por decirlo así, un variado conjunto de opúsculos, que contiene en sus páginas verdaderos extractos ó vulgarizaciones de libros, y se aplica principalmente á servir á la historia, la alta literatura, las ciencias políticas, las bellas artes, la filosofía y la 
crítica. Puede decirse que no tiene del periódico sino la periodicidad, la elasticidad moral y de composición con que se presta á dar cabida á muy diversas materias, y la facilidad relativa con que se adapta, por su precio mucho más reducido que el de los muchos libros que puede contener, á las necesidades intelectuales de un número muy considerable de lectores.

Tiene además la revista periódica dos propiedades que le son características y que, por lo mismo, le dan un modo de ser particular para la acción política. Por una parte, su respetabilidad moral y literaria es tal, así por su serenidad de existencia, fuera de la órbita ardiente del periodismo militante, como por la importancia de los escritores que ordinariamente la sostienen, -que jamás se vulgariza con la colaboración de escritores noveles, subalternos ó de mala nota, ni con escritos insignificantes ó impropios de la alta literatura ó de la ciencia; ni en ningún caso pierde la autoridad adquirida con los buenos escritos, los grandes nombres y la posición que se le reconoce de dignidad en el servicio de las ciencias, las letras, la crítica política y las bellas artes. Por otra parte, llega á formarse con el tiempo un núcleo de redactores y colaboradores tan respetable, y es tan circunspecto de ordinario el tono con que ellos expresan sus ideas en la revista, que ésta adquiere una influencia decisiva y una especie de respetabilidad clásica entre los hombres más pensadores, entre aquellos que pueden estar más cerca de los gobiernos, los parlamentos, los diplomáticos y todos los que con mayor ó menos peso pueden influir sobre la dirección de la política (Samper, 1881, pp. 514-515). ${ }^{8}$

Así pues, en sus diferentes formatos, la prensa literaria colombiana sentó las bases para un tipo de actividad periodística que se ocupó de temáticas que, bajo un concepto amplio de literatura, incluyó diferentes saberes civilizatorios, entre los que se encontraba la historia (Urrejola, 2011, pp. 1683-1732). Como se verá en el siguiente apartado, la prensa ilustrada, en la que se inició Ibáñez, fue asumida como la panacea periodística al combinar las bondades del progreso técnico de la época con el fin de adelantar una labor moralizadora y educativa más efectiva. En tal propósito, el conocimiento del pasado jugaría un papel destacado a través de las colaboraciones de hombres

8 En el mismo sentido, se expresó el político-letrado conservador Carlos Martínez Silva (1878, pp. 1-2). 
como Pedro María Ibáñez, quien veía en la prensa el mejor instrumento para civilizar e infundir el patriotismo.

\section{Ibáñez y la prensa ilustrada}

Heredero directo del semanario americanista Los Andes, fundado en París en 1878, el Papel Periódico Ilustrado (en adelante PPI) representó un parteaguas en el desarrollo del periodismo colombiano. ${ }^{9} \mathrm{Su}$ director, Alberto Urdaneta, hizo de esta empresa una apuesta por articular textos escritos e imágenes de alta calidad para hacer realidad su lema "Pro Patria", en un momento que arreciaba el desencanto y la crítica feroz a la política liberal radical. ${ }^{10}$ El 6 de agosto de 1881, día en el que se conmemoraba un aniversario más de la fundación de Bogotá, vio la luz el primer número del PPI. Con una periodicidad quincenal, tuvo una extensión de dieciséis páginas, en las que se publicaron, por primera vez de forma sistemática, muchos grabados que los lectores coleccionaron como álbum anual (Solano, 2011, pp. 146-156).

El PPI asumió, desde un primer momento, la preocupación por los temas históricos como parte de los gustos e intereses de su director y de los letrados que congregó (Urdaneta, 1992, pp. 7-20). ${ }^{11}$ En palabras del director: "Borramos ochenta años de nuestra vida política, [y] nos trasladamos á Santa Fe” (Urdaneta, 1881) para darle al proyecto periodístico el nombre del primer periódico que tuvo la Nueva Granada. Con el ánimo de difundir conocimientos patrióticos y de progreso, convocó a "los nombres más conspicuos de todos los matices políticos, en las letras, las ciencias y las artes, y los hemos

9 Los Andes fue una tribuna que promovió el progreso material a través de noticias relacionadas con el conocimiento científico y técnico, y los logros literarios de diferentes letrados hispanoamericanos. El director fue Ricardo S. Pereira; la sección científica estuvo a cargo de Ignacio Gutiérrez Ponce y Luis Fonnegra; la literaria fue dirigida por César Guzmán y Roberto de Narváez; mientras que la de bellas artes corrió por cuenta de Alberto Urdaneta. Todos ellos fueron amigos personales de Ibáñez. Ver Los Andes (1878).

10 Para los críticos, el liberalismo radical propició el "caos" y la "anarquía". Una visión general del período en: Sierra (2006).

11 Esta inquietud de Urdaneta la desplegó como coleccionista de documentos, objetos prehispánicos y pintor de obras de contenido histórico. 
reunido en pacífica arena, en campo amigo" (Urdaneta, 1881). ${ }^{12} \mathrm{Si}$ bien la historia contó con una sección independiente que abría cada número, los textos sobre el pasado nacional también aparecieron en otras partes del periódico. ${ }^{13}$ Entre sus principales características, Urdaneta (1881) señaló que:

En esta sección publicaremos los estudios relacionados con la historia patria. Cada número llevará en la primera página el retrato de uno de nuestros hombres notables, y preferiremos por ahora á los héroes de la Independencia. Cada retrato irá acompañado de un bosquejo biográfico, en el cual se condensará los hechos más notables del personaje y los más importantes servicios prestados al país, á fin de que nuestro periódico sirva con el tiempo á manera de álbum nacional. ${ }^{14}$

La publicación de biografías de los héroes de la Independencia dio forma a un panteón jerarquizado de prohombres a los que el lector debía rendir tributo y veneración (Pérez, 2015, pp. 62-72). Como lo plantea Carmen Elisa Acosta (1993), el género biográfico fue uno de los más cultivados por parte de los letrados del siglo XIX (p. 49). En términos generales, se puede decir que el PPI publicó biografías de héroes militares, civiles, locales y letrados, a través de las cuales se apuntaló la operación historiográfica propia de la historia patria que anudó el pasado hispánico con la gesta independentista (Jiménez, 2012, pp. 115-138). Junto a la Independencia, las páginas del quincenario de Urdaneta resaltaron aspectos de la Conquista, como el momento fundacional de la nacionalidad; la antigüedad venerable de la capital, como obra hispánica; y el agradecimiento que debía tributársele a los "valientes" españoles por haber traído la "civilización cristiana". 15

La participación de Pedro María Ibáñez en el PPI se dio luego de su regreso de Europa a Bogotá, en 1882, a donde llegó para asumir cargos y responsabilidades en su calidad de médico. Su primera colaboración data del mes de abril de 1883, justo cuando abandonó

12 La lista de personas invitadas a colaborar se encuentra en Papel Periódico Ilustrado (1881).

13 Las secciones eran: "Ciencias"; "Tipos, vistas y otros"; "Crónicas de Santa Fe"; "Agricultura”; "Lecturas"; "Crónica Interior", y "Contemporáneos".

14 Para más información, ver: González (2011).

15 Estos aspectos corresponden, plenamente, a una posición hispanófila estudiada para el caso colombiano en los textos de Granados (2005, pp. 5-18) y Gracia (2011). 
sus funciones como vacunador oficial, al ser suprimido el cargo por la Junta Central de Sanidad (Biblioteca Personal de Pedro María Ibáñez. Casa Museo Quinta de Bolívar [BPPMI-CMQB], CC 1883). Sus primeros textos en el PPI estuvieron dedicados a la vida de importantes médicos que fueron concebidos como un modelo de patriotismo, a partir de la reconstrucción de sus carreras profesionales al servicio del progreso del país (Ibáñez, 1883a; 1883c). ${ }^{16}$ El interés por rescatar la historia de su profesión se complementó con una serie de trabajos acerca del recorrido de los principales hospitales de la capital (Ibáñez, 1883b; 1884b). Paralelamente, Ibáñez se desempeñaba como corredactor de La Abeja, un medio que se creó para difundir las actividades del Asilo de Niños Desamparados, en donde hizo parte de la junta organizadora del centenario del nacimiento de Simón Bolívar (Ibáñez, 1883d). ${ }^{17}$ En estos relatos, Ibáñez planteó la importancia histórica de la relación entre beneficencia y ciencia como condición de existencia de instituciones "civilizadoras" (Ibáñez, 1883e).

Luego de los trabajos sobre la historia de la medicina, Ibáñez se dedicó a destacar algunos hombres de pensamiento que, a su juicio, merecían ser homenajeados y rescatados del olvido. ${ }^{18}$ Además de dar cuenta de un manejo y conocimiento de la obra de los personajes estudiados, el autor explicitó las dificultades y particularidades de escribir una biografía en el reducido espacio que ofrecía el periódico. Las biografías de personajes del mundo de la ciencia "nacional" y los artículos sobre instituciones benéficas y científicas, permiten pensar en la búsqueda de autolegitimación como hombre de ciencia. Al tiempo, pretendió dotar la historia patria de un cariz menos bélico, al enfocarse en los grandes hombres de pensamiento, en lugar de los héroes militares. ${ }^{19}$

16 En México, el colectivo médico procedió de forma similar, con el fin de obtener legitimidad ante una sociedad que desconfiaba de los galenos. Ver Agostoni (2002, pp. 97-120).

17 Información en tal sentido aparece en: Cervantes, Ibáñez y Herrán (1883).

18 Esta intención se evidencia en otra publicación sobre un personaje vinculado al desarrollo de la mineralogía (Ibáñez, 1884a). Entre los personajes biografiados, estuvieron Víctor Hugo (Ibáñez, 1885b), Benedicto Domínguez (Ibáñez, 1886) y José Antonio de Plaza (Ibáñez, 1887a).

19 Sobre la importancia de los grandes hombres como un tipo civil de la heroicidad en la escritura de la biografía moderna, ver Dosse (2007, pp. 134-166). 
Las páginas del PPI también le permitieron a Ibáñez involucrarse en asuntos relacionados con el devenir de Bogotá. Sus principales objetivos fueron argumentar a favor del cuidado y uso patriótico de algunas edificaciones religiosas y civiles, así como intervenir en debates sobre temas de salubridad pública desde una perspectiva histórica (Ibáñez, 1887b). ${ }^{20}$ Una propuesta que, a la postre, fue aceptada por las autoridades municipales fue el destino que debía dársele a la capilla de la Veracruz, como panteón nacional:

La Veracruz, que guarda los restos venerandos de eximios patricios, sobre cuyas tumbas no existe losa ni inscripción alguna, es Panteón de los hombres ilustres de la revolución, de que fueron víctimas, y como tal debe considerársele. El Gobierno podría reunir allí las cenizas de los jefes que se distinguieron en la guerra de la independencia, hoy dispersos, y levantar un monumento en honra de la memoria de los que allí fueron sepultados durante la lucha, ya que es imposible para éstos colocar sus cenizas en monumentos aislados (Ibáñez, 1885a).

La figuración de Ibáñez en el principal proyecto periódico ilustrado del siglo XIX colombiano, lo llevó a formar parte de un tributo a la memoria de su amigo Urdaneta (Cacua, 1968, p. 179). ${ }^{21}$ Precisamente, la amistad con aquel y las afinidades con esta forma de practicar el periodismo catapultaron a Ibáñez como un colaborador permanente de varios medios que pretendieron mantener el legado del PPI. El primero de ellos fue Colombia Ilustrada, iniciativa dirigida por José Tomás Gaibrois y pensada como un instrumento para generar condiciones de paz, tranquilidad social y armonía en pos del progreso material de la patria. ${ }^{22} \mathrm{~A}$ pesar de las intenciones del grupo redactor y de invitar a plumas noveles y experimentadas en las lides de la escritura patriótica, el primer sucesor del PPI no superó las dieciséis entregas, entre otras razones, por la carencia de público lector

20 Sobre la valoración moralizante contra el consumo de chicha a finales del siglo XIX, ver: Urrego (1997, p. 253).

21 Entre los amigos personales que fueron llamados por Manuel M. de Narváez para rendir tributo a Urdaneta estuvieron Pedro María Ibáñez, Rafael Reyes, José T. Gaibrois y Roberto de Narváez (1888).

22 La relación entre historia y progreso material y moral se advierte en la conmemoración de un aniversario de la Independencia en 1889, en la que se hizo un llamado a la independencia industrial (Colombia Ilustrada, 1889b, pp. 81-112). 
y las dificultades propias del periodismo literario e ilustrado que demandaba una gran inversión de tiempo para la publicación de cada número (Colombia Ilustrada, 1889a; Gaibrois, 1890). En este medio, Ibáñez $(1889 ; 1890 d)$ contribuyó con un artículo sobre los tiempos coloniales en el que se destacaba su afinidad por las costumbres de aquella época, y una biografía de uno de sus maestros en la Facultad de Medicina, ambos en la línea que ya había demostrado.

Un año después del inicio del proyecto de Gaibrois, el grabador español Antonio Rodríguez y su colega Antonio de Narváez, también intentaron mantener el legado de Urdaneta con El Repórter Ilustrado (1890a). Sin embargo, dificultades similares a las de Colombia Ilustrada afectaron la marcha de este proyecto, que solamente alcanzó ocho entregas. Aunque los redactores insistieron en una propuesta de lectura amena, dirigida especialmente a la familia, $E l$ Repórter Ilustrado (1890a; 1890b) estuvo más cerca de los postulados y hombres de la Regeneración, dotando la defensa del progreso material de contenidos conservadores (Marroquín, 1890). En esta ocasión, las colaboraciones de Ibáñez (1890a; 1890c) tuvieron como eje la historia de la capital, particularmente la del poblado aledaño de Facatativá, y la trayectoria de construcciones que sirvieron de escenario a importantes acontecimientos de la historia nacional, cumpliendo una labor divulgativa del pasado local.

Antes de finalizar el siglo, el campo periodístico capitalino vio surgir uno de los últimos intentos por posicionar impresos ilustrados como novedad. El artista liberal Pedro Carlos Manrique (1869-1927) introdujo el fotograbado como uno de los recursos más importantes de la época para ilustrar -en el doble sentido del término- al pueblo lector, con su Revista Ilustrada (1898; Cadavid, 1994, p. 29-43). Bajo el lema "Luz más Luz", la iniciativa defendía que el ideal del progreso fue parte de la lucha por la libertad política, de manera que el componente histórico, que ocupó varias páginas de la revista, se destinó a contar la lucha por la libertad y la prosperidad nacional (Manrique, 1898). Una vez más, Ibáñez (1899a; 1899b) demostró sus dotes como biógrafo al publicar una nueva versión de la semblanza del médico liberal Manuel Plata Azuero (1823-1899) y del héroe antioqueño, José María Córdova (1799-1829), uno de los luchadores más conspicuos en contra de la dictadura bolivariana de 1828 . 
A partir de los años ochenta, la prensa ilustrada sirvió a determinados sectores de las élites culturales y políticas como mecanismo para intentar alejarse de la confrontación partidista. Convencidos de las virtudes moralizantes y edificantes de la imagen, los letrados capitalinos concibieron sus publicaciones como espacios para promover e impulsar el progreso material y moral de la patria. Al ser parte integrante de esta apuesta, el conocimiento de la historia jugó un papel central, ofreciendo modelos de conducta para el público lector. Ibáñez dinamizó esta apuesta con la escritura de varias biografías y textos monográficos, donde procuró contar historias de progreso científico y libertad política que sirvieran de base para la creación de una memoria nacional cuyo eje fuera el pasado capitalino. Esta labor sería profundizada en otros soportes y circuitos letrados como se verá a continuación.

\section{Ibáñez, prensa literaria y revistas culturales}

Luego del golpe militar del general Melo, en 1854, dirigentes de los dos nacientes partidos políticos se arroparon en el civilismo y el patriotismo, para defender un orden social jerarquizado y excluyente (Palacios, 1999, p. 224). En este nuevo ambiente político y social colaboracionista - como ya se ha dicho-, la literatura fue asumida como una arena de encuentro entre sectores enfrentados por cuestiones ideológicas e intereses políticos regionales. ${ }^{23}$ Así fue como surgió, en 1858, El Mosaico, primera y más importante experiencia literaria que contribuyó al establecimiento de una literatura nacional suprapartidista, cuyo fin más importante fue la moralización de la sociedad a través de los cuadros de costumbres (Loaiza, 2004, p. 3-19). La relevancia de este periódico y el grupo de letrados que estuvo detrás de él reside en la grata aceptación por parte del público y la renovación que emprendió en materia de comercialización y circulación de impresos periódicos (Acosta, 1999, p. 13).

$23 \mathrm{Al}$ respecto, es revelador el testimonio de una colaboradora de El Mosaico, sobre el significado del concepto de literatura que involucraba "todo lo que santifica, lo que civiliza, lo que enseña, lo que gobierna, lo que perpetúa, todo lo que encanta al género humano" (Samper de Ancízar, 1860, p. 170, como se citó en Vargas-Tisnés, 2016, p. 140). 
El interés por acendrar un espíritu patriótico permitió que varios de los letrados, entre ellos personajes de gran prestigio cultural, como José María Vergara y Vergara, o el gramático y político José Manuel Marroquín (1827-1908), acudieran a la historia como recurso central para cumplir dicho objetivo (Marroquín, 1864). A través de biografías, cuadros didácticos o comentarios bibliográficos, El Mosaico articuló el pasado, el presente y el futuro de la nación, en torno a un proyecto cultural de corte tradicionalista (El Mosaico, 1859; 1864; Vergara y Vergara, 1859). Dicho relato hablaba de la civilización de los conquistadores, los tiempos de orden y progreso del Virreinato, las jornadas épicas de la Independencia, los años aciagos y de martirio de la Reconquista, y la centralidad de Bogotá como escenario de todas y cada una de las principales etapas del pasado nacional (Vargas-Tisnés, 2016, pp. 302-315).

Luego de esta experiencia, en el último cuarto del siglo XIX y las primeras dos décadas del $\mathrm{xx}$, los periódicos literarios cedieron el lugar a las revistas culturales. Este soporte se diferenciaba de aquellos medios de los años cincuenta en su formato material, que -como se señaló- integraba características y exigencias de uso de la forma libresca y del periódico de actualidad, así como por la conjunción de trayectorias individuales e intereses grupales más definidos, que darían lugar a redes intelectuales con incidencia en la formación del campo intelectual (Beigel, 2003, pp. 105-115; Granados, 2012, pp. 9-20). Estas formas de intervención en la arena intelectual de una época determinada exigen el estudio de las prácticas detrás de los procesos de producción, circulación y consumo, como lo ha enseñado la reciente historiografía latinoamericana (Artundo, 2010, p. 8; Louis, 2014, pp. 34-58; Pita y Grillo, 2015).

En Colombia, a partir de los años setenta del siglo XIX, las revistas culturales fueron tomando cada vez más fuerza, tal y como lo atestiguan los casos de la Revista de Bogotá (1871) y El Repertorio Colombiano (1878), espacios que fortalecieron el proyecto cultural de signo conservador que fue de la mano con un periodismo literario aparentemente neutral. ${ }^{24}$ Así como el PPI ejerció una gran influencia en la

24 La Revista de Bogotá fue dirigida por Vergara y Vergara. El Repertorio Colombiano fue fundado por Carlos Martínez Silva. 
prensa ilustrada, las dos revistas mencionadas sirvieron de referente para una serie de publicaciones literarias que vieron la luz entre 1890 y $1915 .{ }^{25}$ Cada uno de estos proyectos coincidió en otorgarle un lugar destacado al conocimiento histórico como fuente del patriotismo que debía reinar entre los lectores. Las bellas letras, y la historia como parte de ellas, tenían una misión que cumplir como el instrumento "más adecuado y eficaz para darnos cuenta de todas nuestras riquezas materiales y para poder estudiar con éxito todas nuestras necesidades morales del porvenir" (Laverde Amaya, 1890, p. 7, como se citó en Acosta, 1991, p. 19).

De esta forma, entre 1890 y 1894, circuló mensualmente la Revista Literaria, dirigida por el reconocido bibliógrafo bogotano Isidoro Laverde Amaya (1852-1903), quien también estuvo al frente de medios ilustrados en los que manifestó gran interés por los temas históricos. Esta revista reunió en sus páginas a lo más selecto de las plumas residentes en la capital y proclamó abiertamente su interés en "reafirmar, con el recuento de los hechos, la gloria de muchos varones ilustres, difundir aún más, hasta donde sea posible, el interés por los estudios históricos y geográficos que al país conciernen" (como se citó en Acosta, 1991, p. 19). La naturaleza y particularidad de esta publicación residió en la sobriedad de su estilo y diseño, elementos que la aproximaban a una revista académica organizada en secciones estables, sin abandonar la revisión de la vida política bogotana (Laverde Amaya, 1890a).

La importancia que Laverde otorgó a la historia se evidencia en la publicación de adelantos y entregas de obras de reconocidos historiadores como José Manuel Restrepo, Soledad Acosta de Samper o Ernesto Restrepo Tirado, así como de memorias y documentos. ${ }^{26}$ Igualmente, las relaciones políticas y personales del director con las autoridades bogotanas ayudan a entender el interés de la revista por convertirse en una de las principales tribunas de los estudios

25 En el número del mes de mayo de 1890, Colombia Ilustrada saludó la aparición de la Revista Literaria, la cual "viene á acompañarnos en la arena del periodismo literario". Igualmente, el director señaló cómo esta nueva publicación "trae á nuestra mente el recuerdo del Repertorio Colombiano, cuyas huellas parece seguir".

26 Por ejemplo, el texto de Acosta de Samper (1890), hacía parte de una obra mayor sobre la mujer española que arribó a América. 
históricos en el marco de los aniversarios de la Independencia (Laverde Amaya, 1890b). En estas condiciones, Ibáñez (1890e; 1893) figuró como uno de los más prestantes colaboradores, entregando a la Imprenta de La Luz tres textos sobre el movimiento comunero, la instalación de la imprenta en Bogotá y una relación de los arzobispos entre 1533 y 1893 (Revista Literaria, 1890). En su artículo más extenso y completo, este autor ofreció una reinterpretación del levantamiento de 1781, haciendo énfasis en su carácter auténticamente revolucionario y pionero del movimiento independentista. A través de una lectura crítica de la historiografía existente sobre el tema y con base en la consulta de material inédito, los comuneros de Ibáñez (1890b) fueron convertidos en las víctimas del oprobio colonial y padres directos del proceso independentista.

Luego de esta experiencia, y posicionado en la secretaría de la Academia Nacional de Historia, Ibáñez fue invitado, en 1912, a participar de una revista que sintetizó los aspectos más importantes del periodismo ilustrado y las revistas literarias en los albores del siglo xx. La Revista Nacional de Colombia (1912a) articuló la fe en la ciencia, la fotografía y la necesidad de información económica regional, para impulsar inversiones de capital y la creación de un mercado nacional. ${ }^{27}$ Entre los "patrióticos contenidos" que podían contribuir a esta causa, los redactores contemplaron el conocimiento histórico como herramienta para luchar contra la "politiquería", principal obstáculo para alcanzar el progreso. Para ello, Ibáñez fue nombrado como encargado de la sección de "Historia Nacional", en la que se dedicó a exaltar las obras públicas de progreso, el paisaje natural bogotano como escenario del pasado colombiano -a su turno motivo de orgullo para los capitalinos- y los pioneros del republicanismo granadino como continuadores de la causa de la Revolución Francesa (Ibáñez, 1912; 1913a; 1913b).

En el ambiente de progreso que reinó en tiempos del centenario de la Independencia, surgió, a mediados de la década de 1910, un nuevo proyecto revisteril que representaría un consenso en torno a

27 La revista pretendió tener una periodicidad semanal, pero en su primera época logró aparecer quincenalmente, tuvo una extensión de 24 páginas y, al parecer, alcanzó una importante difusión entre los gobiernos departamentales (Revista Nacional de Colombia, 1912a; 1912b). 
la Constitución Política de $1886 .{ }^{28}$ El interés por la política práctica, es decir, por el control de la administración pública, fue el eje que permitió al exalcalde y hombre de letras conservador Emilio Cuervo Márquez (1873-1937) lanzar, en 1915, la Revista Moderna (en adelante RM). Los contenidos históricos, como parte del gusto por lo literario, se entroncaron con la política a partir del siguiente planteamiento: "Si es indispensable tener la vista fija en el futuro, no es conveniente que los hombres olviden la obra inmensa del pasado, de que el presente y ellos mismos son la resultante" (Revista Moderna, 1915, p. 3). Durante sus dos años de existencia, en los que gozó de gran circulación nacional, la RM difundió varios artículos de carácter histórico que, en el caso de Ibáñez, tomaron como marco la conmemoración de la Reconquista española. Estos hechos permitieron reiterar la crítica a los vejámenes de que fueron víctimas los patriotas y la defensa del ideario de la Revolución Francesa, encarnada en la figura del prohombre bogotano Antonio Nariño (Ibáñez, 1915b; 1916).

Las revistas de letras sirvieron para la difusión de trabajos históricos más extensos que no podían ser publicados en la prensa diaria, cada vez más centrada en las noticias de actualidad. Estos textos exigían y presuponían una lectura diferente, menos pasional o informativa, para dar paso a un uso más académico por parte de los eruditos. La prensa ilustrada y las revistas coincidieron en la promoción de una historia para el progreso, "suprapartidista y patriótica" que, en el marco de ciertas coyunturas conmemorativas, explicitaba una defensa de la República y, por contera, una crítica a la restauración monárquica. En el caso de Ibáñez, el nombre que ya había ganado por su trayectoria desde los tiempos del PPI le permitió entregar diferentes colaboraciones a sus amigos redactores, entre los que se destacaron fragmentos de obras más grandes como una estrategia para posicionar su condición de autor de textos históricos (Sapiro, 2016, pp. 105-108). ${ }^{29}$

28 Los aspectos en los que la dirección de la nueva revista consideraba que había consenso suficiente eran la libertad de prensa-como garantía dada por los gobiernos conservadores-, el Concordato con la Iglesia Católica y la necesidad del sistema centralista (Revista Moderna, 1915, p. 2). Para autores como Herbert Braun y Marco Palacios (1999, p. 92), esto se tradujo en la existencia de un grupo de políticos convivialistas, caracterizados como civilistas, antimilitaristas, defensores de las instituciones y amantes de la vida pública.

29 A manera de ejemplo, se encuentra el fragmento que remitió de la segunda edición de las Crónicas de Bogotá (Ibáñez, 1917a). 


\section{Ibáñez y la prensa literaria liberal}

Si bien se ha dicho que la prensa literaria e ilustrada se presentó como apolítica y patriótica, lo cierto es que tal postura constituyó la forma en que ciertos sectores moderados de los dos partidos asumieron el contexto de polarización y pugnacidad dominante. Así fue como algunos miembros del Partido Liberal consideraron la publicación de impresos periódicos literarios un mecanismo para mantenerse activos en la esfera pública, luego de la derrota en la Guerra de los Mil Días e, incluso, antes de esta confrontación (Delpar, 1993, pp. 245-433). Desde luego, la prensa liberal no se circunscribió a las publicaciones moderadas, pues, a finales de siglo, los gobiernos regeneradores persiguieron y censuraron medios y directores radicales y conservadores, a través del destierro, el encarcelamiento y las multas (Pérez, 2014, pp. 181-208). Entre 1894 y 1919, Ibáñez fue cercano a ciertos medios liberales en los que se le reconocía, principalmente, como historiógrafo. El diario Los Hechos, la revista El Gráfico y algunos suplementos literarios de periódicos abiertamente liberales acudieron entonces al saber histórico con fines partidistas.

El primer periódico liberal en el que participó Ibáñez fue en Los Hechos, diario de la tarde dirigido por sus amigos Julio Áñez (1877-1899) y Julio Gálvez. Este medio se caracterizó por expresar un acuerdo parcial con la Regeneración, en temas como la libertad de prensa responsable, sin abandonar la crítica de los asuntos fiscales y de corrupción asociada a los ferrocarriles (Áñez y Gálvez, 1894; Los Hechos, 1894a; 1894b). ${ }^{30}$ En la medida que los redactores y colaboradores buscaban un gobierno "propatria", insistieron en la publicación de textos literarios e históricos tanto en las páginas del folletín -a cargo de Ibáñez en dos ocasiones- como en la parte superior del periódico (Los Hechos, 1894c). Alrededor de este medio gravitaron hombres de letras pertenecientes al círculo cercano de Ibáñez, entre los que se destacó el nombre del periodista, impresor y autor de

30 Cabe recordar que uno de los temas más debatidos en la transición del período radical a la Regeneración fue el abuso en el que, según los liberales independientes y conservadores nacionalistas, incurrieron los liberales al proclamar la libertad absoluta de prensa y consagrarla en la Constitución de 1863. 
obras de historia patria Ignacio Borda. Estos letrados aprovecharon el diario para introducir algunos contenidos históricos asociados al liberalismo dirigidos, principalmente, a las nuevas generaciones de militantes (Los Hechos, 1896a; 1896b; 1896c).

Esta suerte de "liberalismo historiográfico" de Ibáñez se hizo evidente en el centenario del nacimiento de la líder independentista Policarpa Salavarrieta (1795-1817). El texto que publicó sobre la Pola, como se le conocía popularmente, hizo parte de su labor como secretario de una comisión conformada, en su mayoría, por reconocidos jefes liberales, encargada de erigir un monumento a la memoria de la heroína (Los Hechos, 1894d). ${ }^{31}$ A través de un extenso artículo, exhortó a los lectores a participar en dicho proyecto y respondió al poeta Rafael Pombo (1833-1912), quien puso en tela de juicio el lugar de nacimiento de la heroína y la causa de su muerte (Ibáñez, 1894b). La defensa del martirio de Salavarrieta hizo parte de la reivindicación del republicanismo francés y, en general, del ideario de libertad contra el yugo español, representado por Morillo. Una característica distintiva de este texto, publicado en dos entregas, fue el manejo de las fuentes y la construcción de la verdad histórica, a partir de la sumatoria de la revisión crítica de la historiografía, el recuerdo personal de historiadores nacionales reconocidos y la tradición de los habitantes de Guaduas, que esperaban celebrar el nacimiento de su principal hija (Ibáñez, 1894a, p. 642).

Luego de la derrota en la última guerra civil y de la renuncia a la vía bélica para recuperar el poder, el liberalismo moderado tuvo en el centenario de la Independencia un momento de revitalización política y cultural (Posada, 2013, pp. 579-590; Escovar, 2010 pp. 525 559). El ambiente de fe en el progreso y la necesidad de la unidad patriótica fueron asumidos por El Gráfico, semanario que se inspiró en los postulados del republicanismo que representó el político Carlos E. Restrepo (Melo, 1989, pp. 215-242; Palacios, 2003, pp. 98-103). Esta revista gozó de una gran aceptación entre los nacientes sectores medios del país, al tiempo que hizo de la imagen una fuente de conocimiento y atracción para más lectores. Ello se facilitó porque

31 La junta estaba liderada por José María Samper Matiz, Salvador Camacho Roldán y Miguel Samper. Ver: Los Hechos (1894e) e Ibáñez (1894a). 
uno de sus codirectores era el propietario de la tipografía y papelería en que se imprimía el semanario (Marín, 2016, pp. 185-214). Dirigida por Alberto Sánchez, y a diferencia de otros medios liberales, la revista asumió como propia una visión conciliadora del pasado, al promocionar su culto como base del porvenir de la patria, mediante la publicación de documentos, biografías y fotografías (Zapata, 2013, pp. 223-224; El Gráfico, 1910; 1914).

A partir de 1912, el interés por el uso de la historia cobró forma en una sección denominada "Del campo histórico", que sirvió de tribuna para que autores consagrados y nuevos escritores se encontraran en la promoción de las glorias patrias. ${ }^{32}$ Esta sección también fue utilizada para dar a conocer algunos textos de historiadores extranjeros, como el argentino Bartolomé Mitre (1913). Ibáñez figuró como un historiador consagrado que recibió la invitación a publicar en esta sección gracias al viejo lazo personal que lo unía con los redactores, basado en el reconocimiento y admiración que le prodigaban por su larga carrera literaria y su "gusto aristocrático de la historia" (Liévano, 1915). A lo largo de ocho años, Ibáñez publicó siete colaboraciones, reafirmando una concepción moderada y conciliatoria del pasado.

Las contribuciones fueron textos cortos, elaborados a propósito de la conmemoración de algún evento destacado para la memoria del liberalismo, por ejemplo, la resistencia liberal a la toma del convento de San Agustín, en 1860, o los centenarios de la muerte de Nariño (Vanegas, 2015, pp. 385-410) y de algunas heroínas locales de la Independencia (Ibáñez, 1911; El Gráfico, 1911; 1913; 1915). Mención aparte merece el artículo acerca de la fundación de Bogotá y la Batalla de Boyacá, pues si bien apareció en el marco de un aniversario más de estos acontecimientos, presentó una perspectiva revisionista de los mismos. Entre las novedades, propuso cambiar la fecha de erección de la capital, del 6 de agosto de 1538, a abril de 1539, bajo la idea de una fundación político-administrativa; mientras que, de la batalla de 1819, enalteció la dimensión militar de Santander, oscureciendo la figura de Bolívar (Ibáñez, 1915a). Tal y como lo hizo

32 El primer texto de dicha sección fue del médico y liberal moderado antioqueño Manuel Uribe Ángel (1912). 
en otras publicaciones, Ibáñez (1917b; 1919) aprovechó la aceptación de la revista para difundir apartes de la segunda edición de las Crónicas de Bogotá y publicar transcripciones documentales asociadas a la historia reciente del liberalismo.

Como se sabe, en los albores del siglo xx la prensa de actualidad fue ganando espacio frente a los medios dedicados a la opinión, el adoctrinamiento ideológico-partidista y las letras. A mediados de la década de 1910, la gran prensa liberal -El Nuevo Tiempo, El Espectador y El Tiempo- concibió la creación de suplementos literarios bajo aquella vieja preocupación de las élites por ilustrar al "vulgo" con "páginas incontaminadas" de las pasiones políticas (Bedoya, 2016, pp. 125-142; Vallejo, 2006, p 125-126). En 1914, el político liberal y hombre de prensa Eduardo Santos (1888-1974) lanzó Lecturas Populares, suplemento que se publicaría, mensualmente, con su diario El Tiempo, en el que prometía al público una "lectura amena e instructiva", popularizando obras maestras de la literatura universal y nacional, en ediciones baratas y de fácil manejo. ${ }^{33} \mathrm{El}$ conocimiento histórico tuvo un lugar importante en los novedosos suplementos de la gran prensa nacional.

A pocos años de su muerte, y con un nombre ganado entre sus pares y el público culto bogotano, Pedro María Ibáñez hizo parte del selecto grupo de autores que fue popularizado en el suplemento de $E l$ Tiempo. La estructura que siguió este impreso fue la de un folleto de media carta en el que se publicó una semblanza del autor, así como uno o varios textos breves de su pluma. En la noticia biográfica que escribió Nicolás García Samudio, se integró Ibáñez a la pléyade de historiadores nacionales que, desde José María Vergara y Vergara, habían contribuido a la creación de una historia patriótica. Además, su amigo, pupilo y consocio en la Academia de Historia destacó la condición de "bogotano clásico", "correcto prosista" y portador de excelsas cualidades investigativas. Las pruebas de tales virtudes intelectuales fueron los tres escritos que, tomados de las Crónicas de Bogotá, conformaron el folleto (García Samudio, 1914). ${ }^{34}$

33 Para Santos, este espacio debía seguir la senda abierta a fines del siglo anterior por Jorge Roa y su Biblioteca Popular. Ver Pineda (2017, pp. 109-130).

34 Los textos publicados correspondieron al papel conspirador de Nariño, uno de los fundadores de la capital y la señora cucuteña Mercedes Ábrego, sacrificada en la Reconquista. 
Al tiempo que obtuvo la consagración en el diario más importante del país, el médico e historiador fue llamado por el político y veterano liberal de la Guerra de los Mil Días Rafael Uribe Uribe (1859-1914), para que contribuyera al rescate de la memoria de los principales líderes del liberalismo. Así fue como El Liberal Ilustrado también utilizó textos históricos para educar e instruir a sus simpatizantes, con el fin de ganar un espacio en un escenario público dominado por el conservatismo. En él, Ibáñez colaboró con la biografía del poeta bogotano y político antibolivariano Luis Vargas Tejada (1802-1829), quien simbolizaba la defensa de la libertad contra la dictadura, la necesidad de las conspiraciones políticas en determinadas circunstancias, una crítica al poder ejecutivo fuerte y la reivindicación de la figura de Santander, temas rotundamente centrales al liberalismo de principios de siglo (Ibáñez, 1914).

\section{Consideraciones finales}

En la Bogotá de la segunda mitad del siglo XIX e inicios del XX, la prensa literaria e ilustrada fue una condición de posibilidad para el surgimiento y posicionamiento de la historia patria como saber legítimo y reconocido socialmente. A través de este tipo de impresos, los hombres de letras contaron con un espacio para difundir trabajos que, por su extensión y naturaleza, no se ajustaban a las reglas de la prensa política e informativa. Los autores de trabajos históricos aprovecharon tales medios para publicar artículos, documentos y comentarios críticos, dado su menor costo y mayor rapidez de edición en comparación con la producción de libros y folletos. Por sus propósitos declarados, esta prensa asumió el rescate y valoración de las glorias y epopeyas "nacionales" como elemento central de un discurso con evidentes fines identitarios. Para ello, se basó en una concepción amplia de la literatura, en la que se incluían textos de diferentes campos que coincidían en la educación moral, el engrandecimiento de la patria, la superación de la confrontación política y el solaz esparcimiento.

Los objetivos patrióticos proclamados por los redactores y colaboradores de los medios analizados se tradujeron en un supuesto 
alejamiento de la actualidad política, para buscar motivos de orgullo en momentos cuando las disputas políticas afectaban las esperanzas de progreso de las élites conservadoras y liberales. Las particularidades de su proceso de producción explican una periodicidad que no podía ser la misma de los diarios noticiosos o doctrinarios, sino una más espaciada, en la cual semanal, quincenal o mensualmente arribaban a los hogares acomodados para ser leídos en familia. En este contexto, la prensa ilustrada fue un tipo específico de periodismo literario que acopló el uso de la imagen como fuente de conocimiento y educación, tal y como sucedió en diferentes lugares, a lo largo del mundo, durante aquel período (Silva, 2006, pp. 373-406; Aurenche, 2009, pp. 189-218; Román, 2017).

La presencia permanente de Ibáñez en estos medios fue posible gracias a su inserción en un circuito cultural y político conformado por hombres moderados ideológicamente. Heredera de los postulados y de las figuras de José María Vergara y Vergara y de Alberto Urdaneta, la prensa literaria-ilustrada bogotana intentó, en repetidas ocasiones, abrir un campo de reflexión y encuentro sin abandonar la adscripción partidista. Si bien, en términos políticos, dicho personaje estuvo más cerca de las tesis del liberalismo independiente; a nivel cultural, bebió del proyecto que tuvo en las familias Pereira Gamba, Borda o Carrasquilla a los representantes más conspicuos de una visión tradicionalista del país. Como parte de este ambiente, Ibáñez contribuyó a posicionar ciertos temas y planteamientos sobre el pasado local y nacional, a partir de la admiración y respeto por las figuras de primer orden de la república letrada capitalina.

Como se ha procurado mostrar, el "espacio de opinión pública", fuerza y sostén del orden republicano, tuvo un componente histórico destacado en la Colombia que transitó del siglo XIX al XX. ${ }^{35}$ Durante este lapso, la historia tuvo en la prensa un medio fundamental para su constitución como un saber cada vez más específico, con pretensiones de cientificidad, pero sin abandonar la condición de soporte discursivo de las nuevas sociedades políticas como fuente de

35 La relación entre una nueva concepción de la historia, el espacio de opinión pública moderno, el desarrollo de los impresos, y los regímenes políticos democráticos y republicanos es estudiada, para México, por Zermeño (2002, p. 36). 
patriotismo. De forma similar a países como México o Argentina, en donde se ha sugerido la importancia y "obviedad" de la relación entre prensa e historia, en Colombia buena parte de la historiografía nacional y local también circuló en las páginas de la prensa periódica (Lira, 1994, pp. 3-17; Wasserman, 2008, p. 46).

Una de las principales funciones de los impresos periódicos en el posicionamiento del conocimiento histórico en la época estudiada fue la divulgación y difusión del método histórico. Al respecto, la obra de Ibáñez deja ver la importancia que cobró la fundamentación de la escritura histórica en documentos, la pertinencia de un estilo sobrio y la búsqueda afanosa de "objetividad" y "neutralidad", sin afectar el propósito mayor de conciliación, armonía y gratitud hacia los fundadores de la nacionalidad. El diálogo crítico con la tradición historiográfica, la consulta de materiales inéditos e inexplorados como fuente de renovación interpretativa, el uso de la bibliografía disponible con fines revisionistas, la visita directa a lugares históricos y el recurso a la memoria viva fueron algunas de las operaciones realizadas por Ibáñez que, sus lectores pudieron apreciar a través de las revistas y periódicos en los que participó.

La revisión de la obra histórica en prensa de Ibáñez también posibilitó conocer algunas características de la concepción de la historia en el período de estudio, dominada por la idea de esta disciplina como tribunal. Igualmente, a través de este caso se pudo observar la centralidad del género biográfico como la forma de escritura hegemónica sobre el pasado que tuvo como eje la vida de hombres de ciencia, mujeres patriotas y héroes militares. Los artículos estudiados también dejan ver una historia nacional que anudó los dos períodos históricos convencionales, especie de síntesis que se inclinó por la reivindicación de la libertad como valor supremo. Todo ello, en un marco espacial que tuvo a Bogotá como epicentro de los principales acontecimientos del pasado nacional (Urrego, 1997, p. 55).

Finalmente, con la reconstrucción de la trayectoria de Ibáñez como colaborador de la prensa ilustrada y literaria, a lo largo de casi cuatro décadas, se observa cómo esta fue un medio necesario para que los letrados ganaran un nombre en la "Atenas suramericana". El prestigio adquirido por y a través de estas publicaciones periódicas se fundamentó en su moderación política, el estatus científico de 
sus escritos, sus creencias religiosas y sus convicciones republicanas. Tales atributos estuvieron ligados a una importante red de relaciones sociales e intelectuales que hicieron de Ibáñez un protagonista de la formación de la historia patria en uno de los principales soportes de la cultura impresa en el cambio de siglo $\mathbf{C}$

\section{Referencias}

Acosta, C. (1991). Isidoro Laverde y la Revista Literaria: una reflexión sobre la historia de la literatura colombiana. Boletín Cultural y Bibliográfico, 28(27), 18-25. Recuperado de https://publicaciones.banrepcultural.org/index.php/boletin_cultural/article/view/2343

Acosta, C. (1993). Invocación del lector bogotano de finales del siglo XIX: lectura de Reminiscencias de Santafé y Bogotá de José María Cordovez Moure. Bogotá: Instituto Caro y Cuervo.

Acosta, C. (1999). Lectores, lecturas y leídas: historia de una seducción en el siglo XIX. Bogotá: Icfes.

Acosta de Samper, S. (15 de mayo de 1890). La mujer española en Santa Fe de Bogotá (cuadro histórico). Revista Literaria, 1, 41-49.

Agostoni, C. (2005). "Que no traigan al médico": Los profesionales de la salud entre la crítica y la sátira (Ciudad de México, siglos XIX y XX). En: C. Sacristán y P. Piccato (coords.), Actores, espacios y debates en la historia de la esfera pública en la Ciudad de México (pp. 97-120). México: Instituto Mora/UNAM.

Anderson, B. (1993). Comunidades imaginadas: Reflexiones sobre el origen y la difusión del nacionalismo. México: FCE.

Áñez, J. y Gálvez, J. (18 de enero de 1894). Este periódico. Los Hechos, 1, portada.

Artundo, P. (2010). Reflexiones en torno a un nuevo objeto de estudio: las revistas. Recuperado de http://www.memoria.fahce.unlp.edu.ar/trab_eventos/ev.1028/ev.1028.pdf

Aurenche, M. (2009). Londres-Paris-Mexico ou la naissance de la presse périodique illustrée (1830-1850). En L. Andries y L. Suárez de la Torre (dirs.), Impressions du Mexique et de France/Impresiones de México y de Francia, Paris-México (pp. 189-218). París/México: Éditions de la Maison des sciences de l'Homme/Instituto Mora.

Bedoya, G. (2011). La prensa como objeto de investigación para un estudio histórico de la literatura colombiana. Estudios de Literatura Colombiana, 28, 89-109. Recuperado de https://aprendeenlinea.udea.edu.co/revistas/index.php/elc/article/view/10935

Bedoya, G. (2016). Representaciones del intelectual. El suplemento El Nuevo Tiempo Literario en Colombia y su relación con la cultura europea en la primera mitad del siglo XX. Historia Crítica, 59, 125-142. 
Beigel, F. (2003). Las revistas culturales como documentos de la historia latinoamericana. Utopía y Praxis Latinoamericana, 8(20), 105-115.

Cacua Prada, A. (1968). Historia del periodismo colombiano. Bogotá: Fondo Rotatorio de la Policía Nacional.

Cadavid, J. (1994). Revista Ilustrada (1898-1899): De la ilustración al modernismo. Boletín Cultural y Bibliográfico, 31(36), 29-43.

Cardona, P. (2016). Trincheras de tinta: La escritura de la Historia patria en Colombia, 18501908. Medellín: Eafit.

Castaño, L. (2002). La Prensa y el periodismo en Colombia hasta 1888: una visión liberal y romántica de la comunicación. Medellín: Academia Antioqueña de Historia.

Cervantes, Pedro P., Ibáñez, Pedro M., y Herrán, J.L. Circular, Bogotá, 04 de febrero de 1883.

Conrad, S. (2017). Historia global: Una nueva visión para el mundo actual. Barcelona: Crítica.

De Narváez, A. (29 de mayo de 1888). Notas y grabados. Papel Periódico Ilustrado, 116, 323.

Delpar, H. (1993). Rojos contra azules: El partido liberal en la política colombiana, 1863-1899. Bogotá: Tercer Mundo/Museo de Arte Moderno/Procultura.

Dosse, F. (2007). El arte de la biografía: entre historia y ficción. México: Universidad Iberoamericana.

Escovar Wilson-White, A. (2010). Bogotá en tiempos de la celebración del primer Centenario de la independencia. Historia Mexicana, 60(1), 525-559. Recuperado de https://historiamexicana.colmex.mx/index.php/RHM/article/view/1826

Fajardo, M. (1998). Un centenario olvidado: la ilustración editorial en el siglo XIX en Colombia. Ensayos. Historia y teoría del arte, 5, 110-131.

Gaibrois, J. T. (2 de abril de 1889a). Prospecto. Colombia Ilustrada, 1, 2-4.

Gaibrois, J. T. (2 de abril de 1889b). Portada y Cabecera. Colombia Ilustrada, 1, 15.

Gaibrois, J. T. (15 de febrero de 1890). Colombia Ilustrada. Colombia Ilustrada, 9-10, 138.

García Samudio, N. (1914). Doctor Pedro María Ibáñez. Lecturas Populares, III(30), 165-194.

González, J. (2011). La independencia de Colombia en el papel periódico ilustrado, 1881-1888. Bogotá: Universidad Nacional de Colombia.

Gracia, F. (2011). Hijos de la Madre Patria: el hispanoamericanismo en la construcción de la identidad nacional colombiana durante la regeneración (1878-1900). Zaragoza: Institución Fernando el Católico/CSIC.

Granados, A. (2005). Hispanismos, nación y proyectos culturales Colombia y México, 18861921: un estudio de historia comparada. Memoria y Sociedad, 9(19), 5-18. 
Granados, A. Introducción. En Granados, A. (coord.) (2012), Las revistas en la historia intelectual de América Latina: redes, intelectuales, política y sociedad. México: UAMCuajimalpa.

Guerra, F. y Lempérière, A. (1998). Introducción. En F. Guerra y A. Lempérière (coords.), Los espacios públicos en Iberoamérica: ambigüedades y problemas. Siglos XVIII-XIX (pp. 5-21). México: Fondo de Cultura Económica/Cemca.

Habermas, J. (1997). Historia y crítica de la opinión pública: La transformación estructural de la vida pública. Barcelona: Gili.

Hill, C. (2008). National history and the world of nations: Capital, State, and the Rhetoric of History in Japan, France, and the United States. Durham: Duke University Press.

Ibáñez, P. M. (15 de abril de 1883a). D. José Félix Merizalde. Papel Periódico Ilustrado, 38, 218-220.

Ibáñez, P. M. (15 de mayo de 1883b). Relación histórica de los hospitales de Bogotá. Papel Periódico Ilustrado, 41, 278-279.

Ibáñez, P. M. (20 de julio de 1883c). Alejandro Próspero Reverend. Papel Periódico Ilustrado, $45,331-333$.

Ibáñez, P. M. (24 de julio de 1883d). Centenario. La Abeja, 6, 46.

Ibáñez, P. M. (15 de octubre de 1883e). Relación histórica de los hospitales de Bogotá (Fragmentos de las Memorias para la Historia de la medicina en Santafé de Bogotá). Papel Periódico Ilustrado, 52, 55.

Ibáñez, P. M. (febrero de 1884a). Noticia biográfica del Director de Minas D. Juan José D'Eluyar. Anales de Instrucción Pública, 38, 130-133.

Ibáñez, P. M. (1 de abril de 1884b). Relación histórica de los hospitales de Bogotá. Papel Periódico Ilustrado, 62, 222-223.

Ibáñez, P. M. (1 de abril de 1885a). Capilla de la Veracruz. Papel Periódico Ilustrado, 88, 251.

Ibáñez, P. M. (24 de julio de 1885b). Víctor Hugo. Papel Periódico Ilustrado, 95, 362-365.

Ibáñez, P. M. (15 de diciembre de 1886). Benedicto Domínguez. Papel Periódico Ilustrado, $106,146$.

Ibáñez, P. M. (1 de febrero de 1887a). José Antonio de Plaza. Papel Periódico Ilustrado, 109, 198-200.

Ibáñez, P. M. (1 de abril de 1887b). Monarquía y chicha. Papel Periódico Ilustrado, 113, 266-270.

Ibáñez, P. M. (15 de mayo de 1889). Recepción de un virrey en Santa Fe. Colombia Ilustrada, 3, 47-50. 
Ibáñez, P. M. (3 de julio de 1890a). Facatativá. El Repórter Ilustrado, 4, 30-31.

Ibáñez, P. M. (20 de julio de 1890b). Insurrección de 1781: Los Comuneros. Revista Literaria, $3,138-149$.

Ibáñez, P. M. (11 de octubre de 1890c). El puente de Bosa. El Repórter Ilustrado, 8, 61.

Ibáñez, P. M. (22 de octubre de 1890d). Manuel Plata Azuero. Colombia Ilustrada, 17, 264267.

Ibáñez, P. M. (15 de noviembre de 1890e). La imprenta en Bogotá desde su introducción hasta 1810. Revista Literaria, 7, 59-64.

Ibáñez, P. M. (11 de julio de 1894a). Policarpa Salavarrieta (Primer centenario de su nacimiento). Los Hechos, 148, 641-642.

Ibáñez, P. M. (30 de agosto de 1894b). Policarpa Salavarrieta (Primer centenario de su nacimiento). Los Hechos, 187, 810-811.

Ibáñez, P. M. (agosto, 1899a). Manuel Plata Azuero. Revista Ilustrada, 15, 227-228.

Ibáñez, P. M. (septiembre, 1899b). Noticia biográfica del General José María Córdoba. Revista Ilustrada, 16-17, 252-265.

Ibáñez, P. M. (julio, 1893). Cuadro Sinóptico de los Arzobispos de Bogotá: desde la creación de la Silla, 1553-1893. Revista Literaria, 39, 140-141.

Ibáñez, P. M. (febrero, 1911). Un aniversario heroico. El Gráfico, 29, s. p.

Ibáñez, P. M. (16 de marzo de 1912). El Tequendama. Revista Nacional de Colombia, 3, 74-75.

Ibáñez, P. M. (19 de julio de 1913a). El Capitolio y Thomas Reed. Revista Nacional de Colombia, 37, 164.

Ibáñez, P. M. (19 de julio de 1913b). Tres célebres conspiradores. Revista Nacional de Colombia, 37, 163.

Ibáñez, P. M. (11 de julio de 1914). Vargas Tejada. El Liberal Ilustrado, 1034-1035, 71-75.

Ibáñez, P. M. (14 de agosto de 1915a). 6 y 7 de agosto. El Gráfico, 250, 802-803.

Ibáñez, P. M. (noviembre de 1915b). Morillo en Bogotá. Revista Moderna, 11, 370.

Ibáñez, P. M. (26 de julio de 1916). Algo de los años del terror (1816). Revista Moderna, 26, $65-78$.

Ibáñez, P. M. (marzo, 1917a). Viaje de Bolívar a la Costa. Revista Contemporánea, 9, 107-112.

Ibáñez, P. M. (14 de abril de 1917b). Sámano galante. El Gráfico, 341-342, 327-328.

Ibáñez, P. M. (1 de marzo de 1919). Víctimas en 1841. El Gráfico, 458, 64.

Illades, C. (2004). Las revistas literarias y la recepción de ideas en el siglo XIX. Historias, $57,51-64$. 
Jiménez, W. (2012). El Papel Periódico Ilustrado y la configuración del proyecto de la Regeneración (1881-1888). Historia Crítica, 47, 115-138.

Koselleck, R. (2004). Historia/historia. Madrid: Trotta.

Laverde Amaya, I. (15 de mayo de 1890a). Crónica. Revista Literaria, 1, 59.

Laverde Amaya, I. (20 de julio de 1890b). Crónica. Revista Literaria, 3, 193.

Laverde Amaya, I. (1895), Bibliografía Colombiana, Tomo I. Bogotá: Imprenta y Librería de Medardo Rivas.

Liévano, R. (10 de abril de 1915). Entrevistas de El Gráfico-En casa del historiador Ibáñez. El Gráfico, 229-230, 634-635.

Lira, A. (1994). La prensa periódica y la historiografía. En A. Cano Andaluz (coord), Las publicaciones periódicas y la historia de México (pp. 3-17). México: UNAM/Hemeroteca Nacional.

Loaiza, G. (2004). La búsqueda de autonomía del campo literario El Mosaico, Bogotá, 18581872. Boletín Cultural y Bibliográfico, 42(67), 3-19.

Louis, A. (2014). Las revistas literarias como objeto de estudio. En E. Hanno y R. Nanette (eds.), Almacenes de un tiempo en fuga: Revistas culturales en la modernidad hispánica (pp. 31-58). Berlín: Shaker Verlag.

Lyons, M. (2004). Los nuevos lectores del siglo XIX: mujeres, niños y obreros. En G. Cavallo y R. Chartier (eds.), Historia de la lectura en el mundo occidental (pp. 472-517). Madrid: Taurus.

Manrique, P. C. (18 de junio de 1898). Introito. Revista Ilustrada, 1, 1-2.

Marín, P. (2016). Diversificación del público lector en Bogotá (1910-1924). Un análisis de las revistas ilustradas El Gráfico y Cromos. Revista Historia y Memoria, 13, 185-214.

Marroquín, J. M. (24 de septiembre de 1864). Una historia que debería escribirse. El Mosaico, 37, 293-294.

Marroquín, J. M. (3 de julio de 1890). El Lujo. El Repórter Ilustrado, 4, 27.

Martínez, A. (2012). La función estética de las publicaciones ilustradas en Bogotá a finales del siglo XIX. Universitas Humanística, 74, 77-96.

Martínez Silva, C. (julio-diciembre, 1878). [Sin título]. El Repertorio Colombiano, I(1), 1-2.

Melo, J. (1989). De Carlos E. Restrepo a Marco Fidel Suárez. Republicanismo y gobiernos conservadores. En A. Tirado (dir.), La Nueva Historia de Colombia. Tomo I: Historia Política, 1886-1946 (pp. 215-242). Bogotá: Planeta.

Melo, J. (2005). Las revistas literarias en Colombia e Hispanoamérica: una aproximación a su historia. Recuperado de http://www.jorgeorlandomelo.com/bajar/revistas_suplementos_ literarios.pdf 
Mitre, B. (8 de marzo de 1913). Del campo histórico: Retrato de Bolívar. El Gráfico, 124, s. p.

Moreno, P. (1972). Alberto Urdaneta. Bogotá: Colcultura.

Ortega, F. y Chaparro, A. (Eds.), (2012). Disfraz y pluma de todos. Opinión pública y cultura política, siglos XVIII y XIX. Bogotá: Universidad Nacional de Colombia/University of Helsinki.

Osterhammel, J. (2015). La transformación del mundo: una historia global del siglo XIX. Barcelona: Crítica.

Otero, G. (1998). Historia del periodismo en Colombia. Bogotá: Universidad Sergio Arboleda.

Palacios, M. (2003). Entre la legitimidad y la violencia: Colombia, 1875-1994. Bogotá: Norma.

Palacios, M. (1999). Parábola del liberalismo. Bogotá: Norma.

Palti, E. (2007). El tiempo de la política: el siglo XIX reconsiderado. Buenos Aires: Siglo XXI.

Pérez, A. (2010). La independencia como gesta heroica en el continuo histórico nacional: la "densidad" de la representación, 1880-1909. En Las historias de un grito. Doscientos años de ser colombianos (pp. 75-103). Bogotá: Museo Nacional de Colombia.

Pérez, A. (2015). Nosotros y los otros: las representaciones de la nación y sus habitantes, Colombia, 1880-1910. Bogotá: PUJ.

Pérez, S. (2014). Inmorales, injuriosos y subversivos: las letras durante la Hegemonía Conservadora, 1886-1930. Historia y Sociedad, 26, 181-208. DOI: 10.15446/hys. n26.44502

Piccato, P. (2005). Introducción: ¿Modelo para armar? Hacia un acercamiento crítico la teoría de la esfera pública. En C. Sacristán y P. Piccato (coords.), Actores, espacios y debates en la historia de la esfera pública en la Ciudad de México (pp. 9-39). México: Instituto Mora/UNAM.

Pineda, M. (2017). Jorge Roa y la Librería Nueva: Antecedentes y aspectos esenciales sobre el editor colombiano a finales del siglo XIX. Lingüística y Literatura, 71, 109-130.

Pita, A. (2003). Las revistas culturales como fuente de estudio de redes intelectuales. Recuperado de http://www.cialc.unam.mx/Revistas_literarias_y_culturales/PDF/Articulos/Las_ revistas_culturales_como_fuente_de_estudio_de_redes_intelectuales.pdf

Pita, A. y Grillo, M. (2015). Una propuesta de análisis para el estudio de revistas culturales. Recuperado de http://www.memoria.fahce.unlp.edu.ar/art_revistas/pr.6669/pr.6669. pdf.

Posada, E. (2008). Prensa y opinión pública. En E. Ayala (dir.), Historia General de América Latina. Vol. VII: Los proyectos nacionales latinoamericanos: sus instrumentos y articulación, 1870-1930 (pp. 469-487). Madrid: Unesco/Trotta.

Posada, E. (2013). 1910. La celebración del primer centenario en Colombia. Revista de Indias, LXXIII(258), 579-590. 
Rincón, C. (2014). Íconos y mitos culturales en la invención de la nación en Colombia. Bogotá: PUJ.

Román, C. (2017). Prensa, política y cultura visual: El Mosquito (Buenos Aires, 1863-1893). Buenos Aires: Ampersand.

Samper, J. M. (agosto, 1881). [Respuesta en el] Concurso nacional sobre temas científicos, artísticos y literarios (continuación del número anterior). Anales de la Instrucción Pública en los Estados Unidos de Colombia, II(11), 481-549.

Sapiro, G. (2016). La sociología de la literatura. Buenos Aires: FCE.

Sierra, R. (Ed.), (2006). El radicalismo colombiano del siglo XIX. Bogotá: Universidad Nacional de Colombia.

Silva, P. (2006). Un lugar para exhibir, clasificar y coleccionar: la revista ilustrada como una galería de progreso. En B. González y J. Andermann (eds.), Galerías del progreso: museos, exposiciones y cultura visual en América Latina (pp. 373-406). Rosario: Beatriz Viterbo Editora.

Solano, J. (2011). El grabado en el Papel Periódico Ilustrado. Su función como ilustración y la relación con la fotografía. Revista de Estudios Sociales, 39, 146-156.

Urdaneta, A. (6 de agosto de 1881). Historia. Papel Periódico Ilustrado, 1, 4.

Urdaneta, M. (1992). Alberto Urdaneta: vida y obra. Bogotá: BLAA.

Uribe Ángel, M. (20 de noviembre de 1912). Del campo histórico: Un boceto de Santander. El Gráfico, 113, s. p.

Urrego, M. (1997). Sexualidad, matrimonio y familia en Bogotá, 1880-1930. Bogotá: Universidad Central/Ariel.

Urrejola, B. (2011). El concepto de literatura en un momento de su historia: el caso mexicano, 1750-1850. Historia Mexicana, 60(3), 1683-1732.

Vallejo, M. (2006). A plomo herido: una crónica del periodismo en Colombia, 1880-1980. Bogotá: Planeta.

Van Horn Melton, J. (2009). La aparición del público durante la Ilustración europea. Valencia: PUV.

Vanegas, C. (2015). In-visibilidades de la estatua doble del prócer colombiano Antonio Nariño. Anuario Colombiano de Historia Social y de la Cultura, 42(2), 385-410. DOI: 10.15446/achsc.v42n2.53341

Vargas-Tisnés, G. (2016). La nación de los mosaicos: relaciones de identidad, literatura y política en Bogotá (1856-1886). Bogotá: Universidad Externado de Colombia/Academia Colombiana de Historia.

Vasco, J. (2016). Instituciones de la vida literaria y sociedades literarias en Antioquia. Estudio de formas de sociabilidad, 1880-1914 (Tesis doctoral). Universidad de los Andes, Bogotá. 
Villamizar, C. (2014). Colombia/Nueva Granada. En J. Feres (ed.), Diccionario político y social del mundo iberoamericano. Civilización (pp. 185-199). Madrid: Universidad del País Vasco/Centro de Estudios Políticos y Constitucionales.

Wasserman, F. (2008). Entre Clio y la Polis. Conocimiento histórico y representaciones del pasado en el Río de La Plata [1830-1860]. Buenos Aires: Editorial Teseo.

Yujnovsky, I. (2011). Cultura y poder: El papel de la prensa ilustrada en la formación de la opinión pública. Recuperado de http://www.h-mexico.unam.mx/node/6549

Zapata, M. (2013). La opinión pública en el centenario de la independencia. Los casos de Colombia y México (Tesis doctoral). Universidad Nacional de Colombia, Bogotá.

Zermeño, G. (2002). La cultura moderna de la historia: una aproximación teórica e historiográfica. México: El Colegio de México.

Zermeño, G. (2017). Historias conceptuales. México: El Colegio de México.

\section{Archivo}

Biblioteca Personal de Pedro María Ibáñez. Casa Museo Quinta de Bolívar (BPPMI-CMQB), Carpeta Correspondencia 1883, Carta de Eusebio Caro al Sr Vacunador de la Junta C. de Sanidad, Bogotá, 9 de abril de 1883.

\section{Periódicos y revistas}

Colombia Ilustrada (2 de abril de 1889a). "Advertencia”. N. 1, p. 23.

Colombia Ilustrada (20 de julio de 1889b). N. 6-7.

Colombia Ilustrada (31 de mayo de 1890). "Varia”. N. 13, p. 207.

El Eco Literario (8 de julio de 1873). "El agente de periódicos". N. 26, portada.

El Gráfico (26 de noviembre de 1910). "Página histórica-San Mateo". N.. 19.

El Gráfico (septiembre de 1911). "Los restos de Nariño". N. 54, s. p.

El Gráfico (11 de octubre de 1913). “Mercedes Ábrego”. N. 154, p. 27.

El Gráfico (20 de julio de 1914). “Ave patria”. N.. 193-194, pp. 341-342.

El Gráfico (17 de julio de 1915). "Carlota Armero". N. 245, p. 756.

El Mosaico (24 de diciembre de 1858). "El Mosaico". N. 1, p. 1.

El Mosaico (23 de julio de 1859). "Dos publicaciones". N. 30, p. 243.

El Mosaico (27 de febrero de 1864). "Cuadro histórico de la creación de los edificios públicos de Bogotá”. N. 7, p. 56 .

El Repertorio Colombiano (julio-diciembre, 1878). N. 1 . 
El Repórter Ilustrado (4 de junio de 1890a). "Rufino José Cuervo". N. 1, pp. 2-3.

El Repórter Ilustrado (13 de agosto de 1890b). "El Excmo. Sr. Presidente”. N. 13, pp. 50-51.

Los Andes (23 de junio de 1878). Tomo I, N. 1 .

Los Hechos (23 de enero de 1894a). "El periódico". N. 5, p. 17.

Los Hechos (16 de junio de 1894b) "Pro Patria". N. 127, pp. 557-558.

Los Hechos (19 de julio de 1894c). "El libro de la Patria”. N. 155, p. 675.

Los Hechos (25 de septiembre de 1894d). "Centenario de la Pola". N. 208, p. 894.

Los Hechos (5 de octubre de 1894e). “Concurso”. N. 217, p. 934.

Los Hechos (31 de enero de 1896a). "Historia de la Gran Colombia". N. 394, p. 2.

Los Hechos (31 de enero de 1896b). "Gacetilla-Historia de la Gran Colombia, 1810 á 1830". N. $=394$, p. 3.

Los Hechos (18 de julio de 1896c). "Documento histórico”. N. 430, p. 2.

Papel Periódico Ilustrado (1 de octubre de 1881). “Colaboradores”. N.ㄹ 2, p. 22.

Revista de Bogotá (agosto de 1871). N. 1 .

Revista Ilustrada: Crónica, ciencias, artes, literatura, historia (13 de junio de 1898). N. 1, portada.

Revista Literaria (15 de diciembre de 1890). N. 8, pp. 108-116.

Revista Moderna (enero, 1915). "Sin título”. N. 1, pp. 2-3.

Revista Nacional de Colombia (24 de febrero de 1912a). “Circular”. N. 1, pp. 19-23.

Revista Nacional de Colombia (21 de diciembre de 1912b). "A nuestros suscriptores". N. 23, p. 478. 